\title{
The accuracy of officially reported suicide statistics for purposes of epidemiological research
}

\author{
PETER SAINSBURY AND J. S. JENKINS \\ From the Medical Research Council Clinical Psychiatry Unit, Graylingwell Hospital, Chichester, Sussex
}

SUMMARY Suicide is underreported for a number of reasons and the reliability of the official rates is subject to error from variation in defining and reporting cases-the kind of inaccuracies encountered when ascertaining cases in studies of mortality from any cause. Nevertheless, the evidence from studies designed to see whether these sources of error invalidate the differences reported between cultural and social groups indicate that they are randomised, at least to an extent that allows epidemiologists to compare rates between countries and districts within them, between demographic groups, and over time.

The accuracy and hence the value of official suicide statistics has been questioned in recent years to an extent that has led some authorities to dismiss their usefulness in epidemiological research.

Whether an unexpected or violent death is a suicide, that is, an 'act of deliberately taking one's life' (Oxford English Dictionary) is determined at an inquest held by a coroner; similar but by no means identical procedures are followed in other developed countries that report mortality rates. Cases defined and ascertained in this way are the usual source of national suicide statistics. Indeed, it may be claimed that the medical and post-mortem inquiry, together with the evidence of witnesses as to the psychological and social circumstances relating to the act, entail a more thorough investigation into this cause of death than is usual in compiling the statistics of deaths from other causes. Consider, by contrast, the General Register Office inquiry into the accuracy of reporting other causes of death. ${ }^{1}$ When, for example, deaths from cancer of the lung are registered before holding a necropsy and the cause of death is later checked by a pathologist, the net error from false-negatives as well as false-positives is about $16 \%$. The conclusions we draw from the official cancer statistics, however, are not seriously questioned on this account. So it is reasonable to expect suicide statistics, despite inaccuracies, to have heuristic value, particularly as suicide has the distinctive advantage that the number of false-positives is negligible, so only false-negatives - that is, underreporting-need be considered; and that suicide is underreported is not disputed.

The underreporting of suicide has been studied in England and Wales, ${ }^{2}$ Scotland, ${ }^{3}$ and particularly in
Eire. McCarthy and Walsh ${ }^{4}$ examined coroners' case records in Dublin using clinical criteria to assess the probability of suicide. Though their revised rate was considerably higher than the official one, the Irish rate is still exceptionally low when compared with other countries. Barraclough ${ }^{5}$ confirmed, by other means, that the adjusted rate was still half that of England.

In cases of drowning or overdoses, where there is uncertainty whether death was accidental or suicidal, the coroner is likely to err on the side of caution and invoke the legal requirement to establish intent to die even when clinical and other evidence points to suicide. This is borne out by Holding's and Barraclough's $^{6} 7$ comparative studies of matched cases in which the coroner returned a verdict of suicide, of accidental death by poisoning or drowning, and an open verdict, in which the cause of death is undetermined. They found that a high proportion of both accidental and 'undetermined' deaths had the clinical characteristics of the suicides. They therefore inferred that the latter deaths are often misclassified suicides and contribute to the underreporting of suicide. If they assumed that all undetermined deaths were suicides, the official rate might then be underestimated by as much as $22 \%$.

Douglas $^{8}$ and others have concluded that cultural attitudes to suicide determine how suicide is defined, how 'intention to die' is legally interpreted, and how national procedures for obtaining evidence about the death are devised. They claim that these effects, even at a local level, cause coroners to differ in their definitions and their search procedures to an extent that makes official statistics valueless. Accordingly, they contend that the figures are too unreliable to 
compare the suicide rates of countries, districts, or of demographic and other groups; or to discern trends; or to investigate the social relations of suicide. This view has been uncritically accepted by many.

The salient question is whether, despite these sources of errors and biases in identifying cases of suicide, official statistics are sufficiently accurate for the purposes of epidemiological inquiries. In other words, when using data of this kind, are we able to discern valid differences between demographic categories within a population or between districts or between periods in time? For it is by identifying those social categories of the population with high rates of suicide, or by relating the incidence of suicide to the ecological characteristics of districts and its trends to chronological events, that causal hypotheses can be tested and preventive measures proposed. Before presenting formal evidence that official statistics can be used for these purposes, some of their manifest assets should be mentioned.

Firstly, official suicide statistics are unique in their scope: in some countries they have been reported for over a century. For no other aberration of human behaviour is such a wealth of demographic detail available. Secondly, the statutory process for investigating violent deaths goes a long way towards meeting two principal problems of the epidemiological method: it provides an operational definition of a 'case' and finds all such cases in a population, advantages that outweigh any objections about procedural shortcomings. Thirdly, consistent differences in rates between national, demographic, and social groups have been recorded over very long periods; such differences have persisted despite political changes which will have altered the ascertainment procedures in many countries. To ignore the implications of such conspicuous regularities as the higher suicide rates of men, of the elderly, the divorced, and so on, and to dismiss them as errors, is surely failing to see the wood for the trees.

TESTING THE UTILITY OF SUICIDE STATISTICS The more telling rejoinder to those who object that the inaccuracy of suicide mortality figures gainsays their scientific value is to test the conclusions inferred from official statistics against those obtained by controlled case-studies. A survey in which suicide rates were related to the ecology of London illustrates this. It showed that the suicide rates of the boroughs correlate with their social and economic structure. The more affluent districts, for example, had higher suicide rates; as also did those with a high proportion of immigrants. These statistical associations were then confirmed by comparing the economic status and duration of residence of consecutive cases of suicide with that of controls drawn from the general population: the suicides were, in fact, more prosperous and they had moved house more recently than the population at risk. In many other instances, causal hypotheses first suggested by official statistics have been supported by case-studies of suicide. ${ }^{9} 10$

Further evidence that official suicide statistics are sufficiently accurate for most epidemiological purposes, and can thereby contribute to understanding suicide, is as follows.

(1) THE RELIABILITY OF DISTRICT SUICIDE RATES IN CORONERS' DISTRICTS

If coroners vary in their definition of suicide or in their methods of ascertainment, then the differences in rates between coroners' districts would depend on the coroner rather than on the characteristics of the districts. To test this hypothesis, the means of the officially reported suicide rates of the 79 coroners' districts of England and Wales for the two periods 1950-52 and 1960-62 were correlated. This procedure was next repeated for those districts in which the coroners had not changed during the 10 years and for those in which the coroner had changed (exluding districts in which the change occurred in the years during which the means were estimated). As the three coefficients do not differ appreciably (Table 1) we can conclude that the idiosyncrasies of coroners have little practical effect on the differences reported between districts. ${ }^{11}$ When the same

Table 1 Correlations between $(A)$ suicide rates of county boroughs 1950-52 and 1960-62 (B) open verdicts rates of county boroughs 1954-57 and 1964-67 by whether or not coroner changed

\begin{tabular}{llll}
\hline Boroughs & No. & Spearman's $r$ & P \\
\hline (A) All & 79 & 0.42 & 0.001 \\
Same coroner & 39 & 0.45 & 0.01 \\
Different coroner & 19 & 0.49 & 0.05 \\
(B) Sample & 55 & 0.34 & 0.02 \\
Same coroner & 30 & 0.56 & 0.001 \\
Different coroner & 20 & 0.27 & NS \\
\hline
\end{tabular}

Boroughs in which coroner changed in the years during which average was estimated are excluded.

Source: Barraclough ${ }^{12}$

procedure was used to see whether coroners varied in the extent to which they used open verdicts, a change of coroner diminshed the correlation, from which it was inferred that coroners agree quite closely about which deaths they class as suicides, but to a lesser extent about which deaths they allocate to open verdicts rather than to accidental causes. ${ }^{12}$

(2) NATIONAL VARIATION IN ASCERTAINING CASES OF SUICIDE

Atkinson et $a l,{ }^{13}$ on the other hand, compared the verdicts reached by English coroners and by their 
Danish counterparts on the same $\mathbf{4 0}$ cases; but the cases were selected because they were equivocal suicides. They found that the Danes reported a higher proportion as suicides, thereby supporting the view that the ascertainment procedure accounts for Denmark's higher suicide rate, and indeed for national differences in general.

An extension of that study, by the World Health Organisation, ${ }^{14}$ compared methods of ascertainment in 24 countries, and inferred that the verdict depended on the aids available to, and the qualifications of, the officials. More importantly, their assessments of the 40 controversial cases also varied. A warranted conclusion of the WHO report was that many aspects of the procedures for identifying suicides will affect suicide statistics. But the further inferences, that these considerations alone account for variation between countries and that only a 'very limited value can be placed on the official suicide rates', have the appearance of a rather impetuous suicidal attempt on the part of an organisation which annually publishes a unique set of comparative mortality figures.

Ross and Kreitman ${ }^{15}$ also compared the effect on suicide statistics of two markedly different procedures: those followed in Scotland and in England. Their study was far better designed to answer the question whether or not national differences in suicide are due to procedures for identifying cases. The cases seen by the Scottish and English officials were men aged 25-44 and 65-84, because the difference between the two countries is greatest for these demographic groups; the cases were consecutive and therefore unselected, and the numbers were sufficient. The authors found that the Scottish and English officials agreed closely on the cases designated as suicides and they concluded that the ascertainment process did not explain the difference between these countries' suicide rates.

Whether differences in the suicide statistics of nations can be attributed to variations in how their culture defines a case, their society ascertains them, and their officials register them, can also be investigated by controlling for these factors epidemiologically. Sainsbury and Barraclough ${ }^{11}$ attempted to do this by comparing the rank order of the suicide rates of immigrants to the United States of America from 11 different countries with the rank order of the rates reported by their countries of origin (Table 2). Cases of suicide in the various immigrant groups would all have been identified by the procedures common to the USA, whereas suicides in their homelands would have been defined by the methods particular to each country. The rank order of the two sets was nearly identical $(r s=0.90)$. National suicide rates must therefore differ
Table 2 Suicide rates per 100000 of immigrants to the USA for 11 countries for 1959

\begin{tabular}{|c|c|c|c|c|}
\hline \multirow[b]{2}{*}{ Country } & $\boldsymbol{A}$ & $B$ & \multirow[b]{2}{*}{$\begin{array}{l}\text { Rank } \\
\text { order of } \\
A\end{array}$} & \multirow[b]{2}{*}{$\begin{array}{l}\text { Rank } \\
\text { order of } \\
B\end{array}$} \\
\hline & $\begin{array}{l}\text { Suicide ratel } \\
100000 \text { of } \\
\text { foreign-born } \\
\text { in USA (1959) }\end{array}$ & $\begin{array}{l}\text { Suicide ratel } \\
100000 \text { of } \\
\text { country of } \\
\text { origin (1959) }\end{array}$ & & \\
\hline Sweden & $34 \cdot 2$ & $18 \cdot 1$ & 1 & 4 \\
\hline Austria & $32 \cdot 5$ & $24 \cdot 8$ & 2 & 2 \\
\hline Czechoslavakia & $31 \cdot 5$ & 24.9 & 3 & 1 \\
\hline \multicolumn{4}{|c|}{ Germany } & \\
\hline Republic) & $25 \cdot 7$ & $18 \cdot 7$ & 4 & 3 \\
\hline Poland & $25 \cdot 2$ & 8.0 & 5 & 6 \\
\hline Norway & 23.7 & $7 \cdot 8$ & 6 & 7 \\
\hline \multicolumn{5}{|l|}{ Enoland and } \\
\hline Wales & $19 \cdot 2$ & $11 \cdot 5$ & 7 & 5 \\
\hline Italy & $18 \cdot 2$ & $6 \cdot 2$ & 8 & 9 \\
\hline Canada & $17 \cdot 5$ & $7 \cdot 4$ & 9 & 8 \\
\hline Ireland & 9.8 & $2 \cdot 5$ & 10 & 10 \\
\hline Mexico & 7.9 & $2 \cdot 1$ & 11 & 11 \\
\hline $\begin{array}{l}\text { USA } \\
\quad r s=0.90 \\
p<0.01\end{array}$ & $10 \cdot 4$ & & & \\
\hline
\end{tabular}

Source: Sainsbury and Barraclough"11

independently of the ways in which a case of suicide is defined and reported.

It was possible to confirm this, using Australian mortality statistics on 16 immigrant groups ${ }^{16} 17$ (Table 3). The correlations between suicide rates of male immigrants from 16 countries and those of their

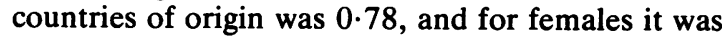
$0 \cdot 79 .{ }^{10}$ Accordingly, we again concluded that national suicide statistics are reliable enough to be used in comparative epidemiological studies.

In order to verify this finding and to meet the specific objection, to which the WHO public health report $^{14}$ also drew attention, that more cases in some countries than in others are allocated to the $I \dot{C} D$ categories of accidental death or 'undetermined' cause of death rather than to suicide, Barraclough ${ }^{18}$ proceeded as follows. He compared the rank order of the officially reported suicide rates of 22 countries ${ }^{19}$ and their rank order of a rate derived by combining their suicide and undetermined death rates. He obtained a correlation of $0.89(p<0.001)$ from which he inferred that this method of controlling for national differences in defining cases of suicide again confirms that the differences are valid, and override those due to discrepancies in the definition and registration of cases.

Using the same technique, we have recently shown that adding accidental poisoning deaths as well as undetermined ones does not materially affect the rank order of the suicide rates of 19 European countries: as can be seen in Table 4, the correlation between the nations' suicide rates and their estimated suicide rates is 0.96 . These results once more support 
Table 3 Suicide rates per 100 000: Australian immigrants and countries of birth, by sex

\begin{tabular}{|c|c|c|c|c|c|c|c|c|}
\hline \multirow[b]{2}{*}{ Country } & \multicolumn{2}{|c|}{ MALE SUICIDE RATES } & & & \multicolumn{2}{|c|}{ FEMALE SUICIDE RATES } & & \\
\hline & $\begin{array}{l}\text { A } \\
\text { Immigrants }\end{array}$ & $\begin{array}{l}\text { B } \\
\text { Country of birth }\end{array}$ & Rank order & $\begin{array}{c}\text { der } \\
B\end{array}$ & $\begin{array}{l}\text { A } \\
\text { Immigrants }\end{array}$ & $\begin{array}{l}\text { B } \\
\text { Country of birth }\end{array}$ & $\begin{array}{l}\text { Rar } \\
A\end{array}$ & $B$ \\
\hline Hungary & $57 \cdot 7$ & $40 \cdot 3$ & 1 & 1 & $34 \cdot 6$ & $17 \cdot 3$ & 3 & 1 \\
\hline Poland & $56 \cdot 6$ & $14 \cdot 3$ & 2 & 7 & $28 \cdot 8$ & $3 \cdot 3$ & 4 & 11 \\
\hline Yugoslavia & 38.6 & $17 \cdot 8$ & 3 & 5 & $16 \cdot 2$ & $7 \cdot 7$ & 7 & 6 \\
\hline Czechoslovakia & $38 \cdot 5$ & $30 \cdot 4$ & 4 & 3 & $45 \cdot 7$ & $12 \cdot 3$ & 1 & 4 \\
\hline New Zealand & $33 \cdot 1$ & $11 \cdot 4$ & 5 & 9 & $19 \cdot 0$ & 6.4 & 5 & 8 \\
\hline Austria & $33 \cdot 0$ & $32 \cdot 4$ & 6 & 2 & $44 \cdot 6$ & $13 \cdot 9$ & 2 & 2 \\
\hline Germany & $32 \cdot 8$ & $26 \cdot 7$ & 7 & 4 & $14 \cdot 5$ & $13 \cdot 6$ & 9 & 3 \\
\hline Ireland & $30 \cdot 5$ & $5 \cdot 3$ & 8 & 14 & $10 \cdot 8$ & $2 \cdot 3$ & 11 & 14 \\
\hline Scotland & $30 \cdot 3$ & $10 \cdot 0$ & 9 & 10 & $17 \cdot 7$ & $6 \cdot 6$ & 6 & 7 \\
\hline USA & $29 \cdot 5$ & $16 \cdot 3$ & 10 & 6 & $13 \cdot 8$ & $5 \cdot 8$ & 10 & 9 \\
\hline England and Wales & $25 \cdot 3$ & $13 \cdot 7$ & 11 & 8 & $15 \cdot 3$ & $9 \cdot 6$ & 8 & 5 \\
\hline Spain & $15 \cdot 9$ & 7.6 & 12 & 12 & $7 \cdot 1$ & $2 \cdot 5$ & 12 & 13 \\
\hline Italy & $10 \cdot 4$ & $7 \cdot 6$ & 15 & 12 & $3 \cdot 4$ & $3 \cdot 2$ & 14 & 12 \\
\hline Greece & $6 \cdot 8$ & $4 \cdot 7$ & 16 & 15 & $3 \cdot 0$ & $2 \cdot 2$ & 15 & 15 \\
\hline \multirow[t]{2}{*}{ Australia } & $16 \cdot 1$ & & & & $10 \cdot 0$ & & & \\
\hline & \multicolumn{6}{|c|}{$\mathrm{rs}=0.78$} & \multicolumn{2}{|c|}{$\mathrm{rs}=0.79$} \\
\hline
\end{tabular}

Source: Whitlock ${ }^{16}$

the more probable notion that a country's official death statistics do, in fact, describe its incidence of suicide relative to other countries.

(3) VARIATION IN CASE-FINDING OVER TIME: VALIDATION OF TRENDS

The objection that the definition of a case may change over the years and so diminish the confidence with which suicide trends and their association with, say, major socioeconomic events can be interpreted also needs to be considered.

We therefore asked whether the sharp decline in suicide in England and Wales between 1961 and 1974 in all age groups, with the exception of women aged 15-24 (see the Figure from Adelstein and Marden ${ }^{20}$ ), could be explained by various administrative and legal events which might have affected either the definition of suicide or coroners' attitudes to giving this verdict. ${ }^{21} 22$ We looked at three events during this period.

The first was the Suicide Act of 1961 whereby attempting or committing suicide ceased to be a criminal offence. This might have led to a greater readiness to bring in a verdict of suicide, but when the mean rates of men and women aged 15 and over for 1958-60 were compared with those for 1961-63, the female rate increased by $7 \%$ whereas the male rate decreased slightly. This difference between the trends of men and women, and the progressive decline in both after 1964, make it improbable that the new act had any effect.

The second event was the revision of the $I C D$ in 1967. This may have led to fewer cases being allocated to 'suicide', because it introduced a new cause of death which enabled open verdicts to be classified as 'undetermined' whether suicide or accident.

Since coroners are often reluctant to designate a violent death as a case of suicide, the effect of the

Table 4 Comparison of the rank orders of suicide rates and suicide, undetermined and accidental poisoning death rates in 19 countries in 1970-73

\begin{tabular}{|c|c|c|c|c|}
\hline Country & $\begin{array}{l}\text { Suicide and } \\
\text { self-inflicted } \\
\text { injury }\end{array}$ & $\begin{array}{l}\text { Rank } \\
\text { order }\end{array}$ & $\begin{array}{l}\text { Suicide and self-inflicted } \\
\text { injury and injury } \\
\text { undetermined whether } \\
\text { purposely or } \\
\text { accidentally inflicted } \\
\text { and accidental } \\
\text { poisoning }\end{array}$ & $\begin{array}{l}\text { Rank } \\
\text { order }\end{array}$ \\
\hline Austria & 30.4 & 4 & 33.0 & 6 \\
\hline Bulgaria & $15 \cdot 1$ & 11 & 19.0 & 11 \\
\hline Czechoslovakia & 31.0 & 2 & 39.8 & 3 \\
\hline Denmark & 30.6 & 3 & 36.4 & 4 \\
\hline Finland & 29.7 & 5 & 40.8 & 2 \\
\hline France & 20.4 & 9 & $25 \cdot 1$ & 9 \\
\hline Germany & 26.8 & 6 & 29.6 & 7 \\
\hline Greece & $4 \cdot 1$ & 19 & $7 \cdot 1$ & 18 \\
\hline Hungary & $45 \cdot 2$ & 1 & $48 \cdot 5$ & 1 \\
\hline Italy & $7 \cdot 6$ & 16 & $9 \cdot 2$ & 17 \\
\hline Netherlands & $11 \cdot 3$ & 13 & $12 \cdot 9$ & 15 \\
\hline Norway & 11.4 & 12 & $14 \cdot 2$ & 14 \\
\hline Poland & 15.5 & 10 & $23 \cdot 1$ & 10 \\
\hline Spain & 5.9 & 17 & 6.8 & 19 \\
\hline Switzerland & $24 \cdot 6$ & 8 & $27 \cdot 2$ & 8 \\
\hline \multicolumn{5}{|l|}{ England and } \\
\hline Wales & $10 \cdot 3$ & 15 & $15 \cdot 5$ & 13 \\
\hline \multicolumn{5}{|l|}{ Northern } \\
\hline Ireland & $5 \cdot 4$ & 18 & $11 \cdot 0$ & 16 \\
\hline Scotland & 10.6 & 14 & $17 \cdot 6$ & 12 \\
\hline Sweden & 26.4 & 7 & $36 \cdot 0$ & 5 \\
\hline
\end{tabular}

Spearman's rank correlation $=0.9596 \quad n=19 \quad p<0.001$

Source: original data 
revision can also be examined by adding 'undetermined' and accidental poisoning deaths to the suicides to arrive at an 'estimated' rate. When this is done, the age and sex trends of the 'combined' or 'estimated' rate virtually parallel those of the suicide rate alone (see the Figure) but no changes in age and sex can be discerned after the revision in 1967.

In this context it is appropriate to mention that some vital statisticians advocate combining cases of suicide with undetermined and certain accidental deaths (by poisoning and drowning especially) in order to obtain a truer 'estimate' of the suicide rate. It is difficult to understand what is gained because, as has just been shown, estimating suicide figures in this way does not alter the pattern of trends appreciably. What it manifestly does do is to introduce other potential sources of error in defining cases of suicide by arbitrarily reappraising the coroner's verdict without reference to the information on which he based his decision and by assuming all accidental
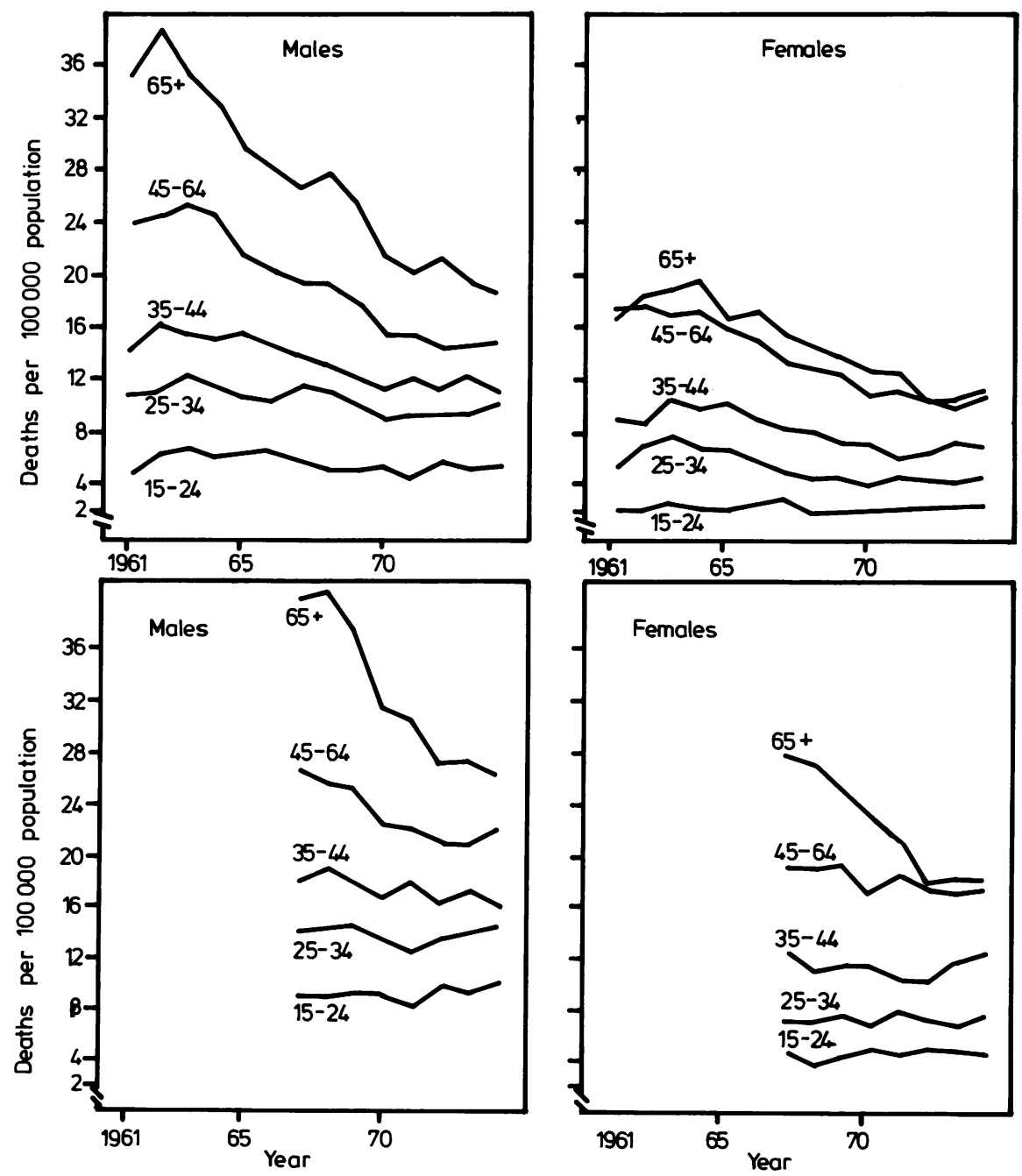

Figure Suicide rates by sex and age group 1961-74, England and Wales, and 'estimated' suicide rates by sex and age group 1967-74, England Wales. Source of suicide rates: ICD 7th revision (E970-E979) and 8th revision (E950-E959). Source of 'estimated' suicide rates: ICD 8th revision (Suicides E950-E959. Open verdicts E980-E989. Accidental poisoning E850E877).

The 1974 rates are provisional. This Figure is from Adelstein and Marden. ${ }^{20}$ 
Table 5 The ratio of poisoning deaths by suicide to poisoning deaths allocated to accidental and open verdicts, England and Wales 1961-72

\begin{tabular}{|c|c|c|c|c|c|c|c|c|c|c|c|c|}
\hline Poisoning deaths & 1961 & 1962 & 1963 & 1964 & 1965 & 1966 & 1967 & 1968 & 1969 & 1970 & 1971 & 1972 \\
\hline \multirow{2}{*}{$\begin{array}{l}\text { (A) Suicide } \\
\text { (B) Accidental and } \\
\text { open verdicts }\end{array}$} & 784 & 1082 & 1389 & 1502 & 1497 & 1444 & 1418 & 1416 & 1390 & 1263 & 1229 & 1159 \\
\hline & 1478 & 1831 & 2072 & 1762 & 1643 & 1768 & 1601 & 1535 & 1609 & 1544 & 1551 & 1398 \\
\hline Ratio of $A: B \times 100$ & 53 & 59 & 67 & 85 & 91 & 82 & 89 & 92 & 86 & 82 & 79 & 83 \\
\hline
\end{tabular}

The trend is for the ratio to increase, though from 1964 onwards, it is fairly stable. If accidental poisoning and open verdicts were to increase, because more suicides are being allotted to these verdicts, then the ratio would decrease.

poisoning deaths are suicides, which they clearly are not. It therefore seems preferable to retain the present convention of basing suicide rates solely on the number of coroners' verdicts of suicide, without speculating whether a figure closer to a spurious 'true' rate of suicide is obtained if deaths from these other causes are included.

Thirdly, in 1967 and on five subsequent occasions, the coroners' verdicts of suicide were challenged in a higher court. The effect of this novel criticism of coroners might have been to make them adopt a more cautious definition of suicide, especially in cases of poisoning.

The theory that suicide trends are invalidated by misclassifying poisoning deaths is again not supported by the evidence from 'estimated' rates (see the Figure). The fact nevertheless remains that poisoning is becoming the favoured means of suicide and it is in cases of this kind that coroners are likely to find it difficult to decide between suicide and accident. So the further observation that the ratio of

\section{References}

${ }^{1}$ General Register Office. Accuracy of certification of cause of death. Studies on medical and population subjects no. 20. London: HMSO, 1966.

${ }^{2}$ Seager CP, Flood RA. Suicide in Bristol. Br J Psychiatry 1965; 111: 919-32.

${ }^{3}$ Ovenstone IMK. Spectrum of suicidal behaviours in Edinburgh. Br J Prev Soc Med 1973; 27: 27-35.

${ }^{4}$ McCarthy PD, Walsh D. Suicide in Dublin. I: The under-reporting of suicide and the consequences for national statistics. Br J Psychiatry 1975; 126: 301-8.

${ }^{5}$ Barraclough BM. The different incidence of suicide in Eire and in England and Wales. Br J Psychiatry 1978; 132: 36-8.

${ }^{6}$ Holding TA, Barraclough BM. Psychiatric morbidity in a sample of a London coroner's open verdicts. $\mathrm{Br} J$ Psychiatry 1975; 127: 133-43.

${ }^{7}$ Holding TA, Barraclough BM. Psychiatric morbidity in a sample of accidents. Br J Psychiatry 1977; 130: 244-52.

${ }^{8}$ Douglas JD. The social meanings of suicide. Princeton: Princeton University Press, 1967.

${ }^{9}$ Sainsbury P. Suicide in London. Maudsley Monograph No. 1. London: Chapman and Hall, 1955.

${ }^{10}$ Sainsbury P. Suicide: opinions and facts. Proc R Soc Med 1973; 66: 579-87.

"Sainsbury P, Barraclough BM. Differences between suicide rates. Nature 1968; 220: 1252.

${ }^{12}$ Barraclough BM. The effect that coroners have on the suicide rate and the open verdict rate. In: Hare $E$, Wing J, eds. Psychiatric epidemiology. London: Oxford suicides by poisoning to deaths by poisoning given accidental or open verdicts was nearly the same in 1972 as in 1967 endorses the conclusion that the relative increase in poisoning as a means of suicide has not substantially affected the accuracy of the reported trends in suicide (Table 5).

The view that errors in reporting are randomised over the years is also supported by Brugha's and Walsh's study ${ }^{23}$ of the temporal constancy of underreporting suicide in Ireland. They found the underestimation by coroners in Dublin during 1900-1904 was the same as in 1964-1968. Consequently they inferred that the official statistics validly describe trends and can therefore be used to study the effects on suicide of socioeconomic or other temporal changes.

Reprints from Dr. Peter Sainsbury, Director, MRC Clinical Psychiatry Unit, Graylingwell Hospital, Chichester, Sussex PO19 4PQ.

University Press, 1970: 361-5.

${ }^{13}$ Atkinson MW, Kessel WIN, Dalgaard JB. The comparability of suicide rates. Br J Psychiatry 1975; 127: 247-56.

${ }^{14}$ World Health Organisation. Brooke E, ed. Suicide and attempted suicide. Public health paper no. 58. Geneva: WHO, 1974.

${ }^{15}$ Ross O, Kreitman N. A further investigation of differences in the suicide rates of England and Wales and of Scotland. Br J Psychiatry 1975; 127: 575-82.

${ }^{16}$ Whitlock FA. Migration and suicide. Med J Aust 1971; ii: 840-8.

${ }^{17}$ Lester D. Letter. Med J Aust 1972; i: 941.

${ }^{18}$ Barraclough BM. Differences between national suicide rates. Br J Psychiatry 1973; 122: 95-6.

${ }^{19}$ World Health Organisation. World health annual statistics 1968. Vol. 1: Vital statistics and causes of death. Geneva: WHO, 1971.

${ }^{20}$ Adelstein A, Marden C. Suicides: 1961-1974. Population Trends No. 2. London: OPCS, 1975: 13-18.

${ }^{21}$ Sainsbury P, Jenkins J, Baert A. Suicide trends in Europe: A study of the decline in suicide in England and Wales and the increase elsewhere. Copenhagen: WHO (in press).

${ }^{22}$ Jennings C, Barraclough BM. Legal and administrative influences on the English suicide rate, 1900. Psychol Med 1980; 10: 407-18.

${ }^{23}$ Brugha T, Walsh D. Suicide past and present-the temporal constancy of under-reporting. Br J Psychiatry 1978; 132: 177-9. 